\title{
The effects of pipeline construction disturbance on soil properties and restoration cycle
}

\author{
Peng Shi • Jun Xiao • Ya-Feng Wang • Li-Ding Chen
}

Received: 5 July 2013 / Accepted: 10 October 2013 /Published online: 19 October 2013

(C) Springer Science+Business Media Dordrecht 2013

\begin{abstract}
Disturbance to the physical-chemical properties of soil caused by pipeline installation was evaluated using two soil quality indices to identify the scale of disturbance and the restoration cycle. The integrated soil quality index (SQI) was used to evaluate soil property changes in different pipeline zones $(0,10,20$, and $50 \mathrm{~m}$ from the pipeline) at sites 1 and 2 . The soil restoration index (SRI) was used to estimate soil recovery from three pipelines with different recovery periods $(2,6$, and 8 years) at site 3 . The results showed that the adverse effects of pipeline construction on soil properties mainly occurred in the right-of-way (ROW) areas and the impaired zones were in the order trench> piling and working areas $>20$ and $50 \mathrm{~m}$. The soil restoration cycle may be complete within 6 years of construction. At site 3, the SRI in the ROW area of a pipeline after 6 years of restoration was close to $100 \%$, showing full soil recovery. However, the SRI in the disturbed areas of a pipeline after 2 years of restoration was much lower than that after 6 years of restoration, indicating that the soil was still recovering from the disturbance. The topography may change the intensity of disturbance in different areas due to the movement patterns of heavy machinery and traffic routes. There were local variations in the SQI within the pipeline
\end{abstract}

P. Shi $\cdot$ J. Xiao $・$ Y.-F. Wang $\cdot$ L.-D. Chen $(\varangle)$

State Key Laboratory of Urban and Regional Ecology,

Research Center for Eco-Environmental Sciences,

Chinese Academy of Sciences, Beijing 100085, China

e-mail: liding@rcees.ac.cn

P. Shi $\cdot$ J. Xiao

University of Chinese Academy of Sciences,

Beijing 100049, China zones, with flat areas suffering greater disturbance than hilly areas, indicating that topography should be considered in a pipeline's environmental impact assessment.

Keywords Environmental impact assessment . Distance $\cdot$ Disturbance $\cdot$ Pipeline $\cdot$ Soil quality . Restoration cycle

\section{Introduction}

Natural gas or oil pipeline projects are important for economic development in West China and as energy sources for East China (Chen et al. 2012). Inevitably, pipeline installation involves extensive disturbance that may directly and indirectly influence the soil system in the surrounding area (Chen and Gao 2006). During construction, ground excavation can reduce land stability and increase soil erosion, especially in mountainous regions (Yu et al. 2010). Various studies indicate that soils inside a pipeline corridor have a lower organic matter and a higher $\mathrm{pH}$ than undisturbed soils (Soon et al. 2000a; Kowaljow and Rostagno 2008). Trenching to install underground pipelines may change the soil profile by mixing different soil horizons (Olson and Doherty 2012). Irregular stacking of spoil also alters the soil characteristics, particularly its physical and chemical properties, by mixing more fertile topsoil with less fertile subsoil (Desserud et al. 2010). Soil compaction occurs in heavy-traffic areas during construction, leading to long-term structural decline (Yu et al. 2010). Despite the monitoring and mitigation efforts following state-required environmental impact 
assessments (EIAs), pipeline construction may still have pronounced effects on agro-ecosystems, thus influencing land productivity.

Soil quality is an important aspect of agro-ecosystems, and the maintenance of soil quality is of great importance for agricultural sustainability (Arshad and Martin 2002). The most essential attributes of soil quality are defined as "sustaining productivity, maintaining environmental quality and supporting human health" (Karlen et al. 1997). The ability of soil to enhance crop production is one of the basic components of soil quality indices (Bone et al. 2010). Soil quality has a linear correlation with crop yields, with more than $70 \%$ of the variability in crop yields being explained by soil quality scores (Mueller et al. 2013).

Physical, chemical, and biological factors have been suggested as indicators of soil quality (Zornoza et al. 2007; Bone et al. 2010). A variety of definitions of soil quality have been proposed with similar elements (Karlen et al. 1997; Patzel et al. 2000; Bone et al. 2010), and many methods have been proposed to evaluate soil quality (Andrews et al. 2002; Romaniuk et al. 2011). Although regarded as a basic concept of soil monitoring (Kaufmann et al. 2009), soil quality is not always used in or applied to EIAs. General soil properties such as $\mathrm{pH}$, organic matter, and nitrogen are commonly used to assess soil disturbance. Soon et al. (2000b) found that pipeline burial increased the soil $\mathrm{pH}$ and electrical conductivity. Soil compaction and topsoil removal during oil pipeline construction resulted in significant decreases in soil organic matter and nitrogen and phosphorous contents (Woodward 1996). Coiffait-Gombault et al. (2011) reported that pipeline construction affected soil $\mathrm{C} / \mathrm{N}$, $\mathrm{pH}$, and $\mathrm{CaO}$.

Although concerns about the ecological disturbances of large-scale infrastructures such as oil and gas pipelines are increasing, few quantitative EIAs have attempted to determine the scale of disturbance and the restoration cycle. Without determining the boundaries of spatial and temporal disturbance, it is difficult for practitioners producing state-required EIAs to choose scientifically appropriate scales (Karstens et al. 2007). João (2002) questioned whether EIA results were more an artifact of the scales used than the real world. Large boundaries increase uncertainty, while small boundaries may not adequately encompass all of a project's environmental impacts (Canadian Environmental Assessment Agency 1996). The assessment boundary is often limited by the available budget and time.
Generally, pipeline construction zones receive compensation for the year of construction in the rightof-way area. It is important to accurately determine the borders of the affected areas and the restoration time to justify the compensation for the affected farming community. Environmental monitoring is necessary to confirm the duration of soil restoration. Allowing a certain time for soil restoration will improve the effectiveness of follow-up mitigation. Pipeline installation involves extensive disturbance to soil systems that may change with different terrains, some of which need more time to restore. As pipelines in China, such as the West-to-East Gas Pipeline, are trenched through a variety of terrains, this should be taken into consideration in EIAs to estimate the real disturbance across different terrains. Laying a pipeline on a plain involves the use of heavier machinery than is used in a hilly region. Different intensities of human activities may also influence the scale and extent of soil disturbance.

The objectives of this study were to (1) estimate the effects of pipeline installation on the soil properties and soil quality at different distances from the pipeline and the borders of the impaired for soil monitoring; (2) verify whether topography affects soil disturbance due to pipeline construction; and (3) identify the temporal duration of soil restoration after human disturbance.

\section{Materials and methods}

\section{Study areas}

Construction of the West-to-East Gas Pipeline I (WEGP I) began in 2002, and the pipeline was put into pilot operation in 2004 . Nearly $4,000 \mathrm{~km}$ long and with a diameter of $1,016 \mathrm{~mm}$, the pipeline passes through Xinjiang, Gansu, Ningxia, Shaanxi, Shanxi, Henan, Anhui, and Jiangsu and terminates in Shanghai (Fig. 1). Another large pipeline project in China, the West-to-East Gas Pipeline II (WEGP II), was constructed from 2008 to 2010 . The main pipeline is $4,843 \mathrm{~km}$ long and runs from northwestern Xinjiang to Guangzhou in Guangdong province. It took 2 years to build the 4,000-km-long West Crude Oil Pipeline (WCOP) between 2005 and 2006, starting from Urumqi, Xinjiang Uygur Autonomous Region, and ending at Lanzhou, Gansu province. Up to Gansu, WCOP runs parallel to WEGP I and WEGP II. 


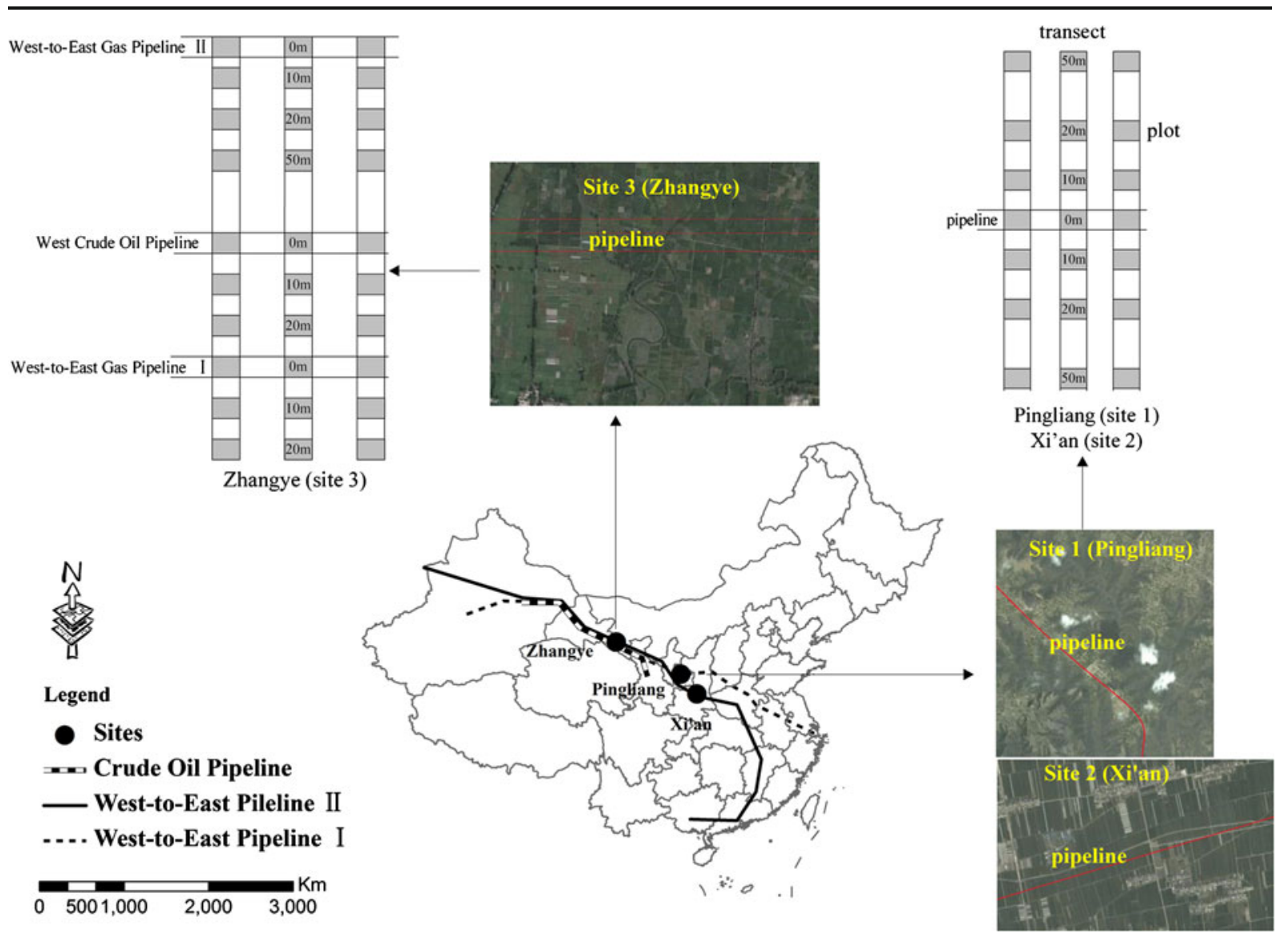

Fig. 1 Sample sites and design of transects for sampling soils along the West-to-East Gas Pipeline I (WEGP I), West-to-East Gas Pipeline II (WEGP II), and West Crude Oil Pipeline (WGOP). Site 1 was in Pingliang and site 2 was in Xi' an, both of which had only one pipeline passing through. Plots of $1 \times 1 \mathrm{~m}$ were laid out at

Three sites were set up in typical agricultural regions of China for soil sampling in this study: Pingliang (site 1) and Zhangye (site 3) in Gansu province and Xi'an (site 2) in Shaanxi province (Fig. 1). The right of way (ROW) of all three pipelines passed through site 3, and WEGP I and WEGP II passed through sites 1 and 2, respectively. Sites 1 and 2 were chosen to study the spatial boundary of the soil impact assessment. Site 3 was used to define the temporal duration of soil restoration after disturbance; the cumulative influence of the different pipelines, $100 \mathrm{~m}$ apart from each other, was ignored. At all three sites, the pipeline's ROW was through farmland growing corn crops. Site 1 mainly comprises loess with texture ranging from fine silt to silt and is characterized as gentle slope hilly farmland (10\% slope). Site 2 has sandy loam-textured soil and the topography is almost distances of $0 \mathrm{~m}$ (trench area), $10 \mathrm{~m}$ (piling and working areas), and 20 and $50 \mathrm{~m}$ from both sides of the pipeline for soil sampling at sites 1 and 2. Site 3 was in Zhangye, where all three pipelines had right of way. Plots were set 0,10 , and $20 \mathrm{~m}$ away from one side of each pipeline and $50 \mathrm{~m}$ from WEGP II as a control

flat (0-1\% slope) throughout the study area. Site 3 has a slope of $0-1 \%$ with a bleached, sandy textured soil.

Sampling methods

The pipeline ROW area of 28-30 m was divided into three zones (Fig. 2): a trench where the pipeline was buried ( $2 \mathrm{~m}$ wide in the middle of the ROW), a working area used for vehicular traffic (2-15 m away from one side of the trench), and a piling area cleared to stockpile the topsoil and subsoil stripped from the pipeline ROW (2-15 $\mathrm{m}$ away from the other side of the trench). In August 2012, three transects were set up perpendicular to the pipeline at each site with similar topography and soil characteristics, at least $500 \mathrm{~m}$ away from each other (Fig. 1). Soil samples were collected from the plots along each transect at distances of $0 \mathrm{~m}$ (trench), $10 \mathrm{~m}$ (piling or 


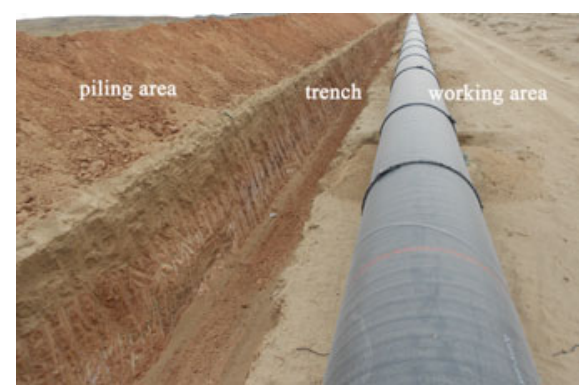

Fig. 2 Pipeline right of way, including the trench, piling, and working areas

working area), and 20 and $50 \mathrm{~m}$ from both sides of the pipeline at sites 1 and 2 . The three pipelines are parallel to each other at site 3 , where plots were set $0 \mathrm{~m}$ (trench), $10 \mathrm{~m}$ (working area), and $20 \mathrm{~m}$ away from one side of each pipeline, with a further plot set $50 \mathrm{~m}$ from WEGP II as a control. A $1 \times 1-\mathrm{m}$ plot was laid out for sampling within the designated distance on each transect. Five randomly selected cores were taken to a $40-\mathrm{cm}$ depth in three segments $(0-10,10-20$, and 20-40 cm). About 216 composite soil samples were taken from the three sites.

\section{Laboratory analysis}

All of the soil samples were air-dried, ground, and sieved through a 2-mm and then a 1-mm screen for soil chemical analysis. Soil $\mathrm{pH}$ was measured at a soil-to-water ratio of 1:2.5 using a Crison GLP $21 \mathrm{pH}$ meter (Crison Instruments, Spain). Soil organic matter (SOM) was determined using colorimetric determination (Sims and Haby 1971). Total nitrogen (TN) and total carbon (TC) were quantified with an elemental analyzer (Vario EL III, Germany). Total phosphorus (TP) and total potassium (TK) were extracted by microwave digestion and measured using inductively coupled plasma optical emission spectrometry (Agilent Technologies, USA). Alkali hydrolyzable nitrogen (AN) was determined using the method described by Cornfield (1960). Soil available phosphorus (AP) was extracted with $0.5 \mathrm{~mol} / 1 \mathrm{NaHCO}_{3}$ at $\mathrm{pH}$ 8.5. Soil particle sizes were analyzed using the MasterSizer 2000 apparatus (Malvern, Britain). The proportion of clay $(<0.002 \mathrm{~mm})$ content was then calculated.

Data analysis

SPSS16.0 ${ }^{\circledR}$ was used for statistical analysis. The means of the soil parameters and soil quality indices were compared using one-way ANOVAs to analyze the variance in the different zones due to the pipeline and soil restoration. Two integrated indices, the integrated soil quality index (SQI) and soil restoration index (SRI), were calculated to evaluate the effect of the pipeline construction on the soil properties. The SQI integrates the physical and chemical indicators of the soil and provides a comprehensive, quantitative assessment of the soil quality. The SRI was used to indicate the degree of soil recovery following the pipeline construction disturbance.

\section{Integrated soil quality index}

The continuous membership functions were used to score the indicator. Two kinds of continuous membership functions, ascending (Eq. 1) and descending (Eq. 2) properties, were determined by the positive or negative value of the capacity score coefficient of the principal component analysis (Fu et al. 2003). AN, AP, TN, TP, TC, SOM, and $\mathrm{pH}$ were scored using Eq. 1 and clay scored using Eq. 2. The continuous membership functions are listed as follows:

$$
\begin{aligned}
& Q\left(x_{i}\right)=\left(x_{i j}-x_{i \min }\right) /\left(x_{i \max }-x_{i \min }\right) \\
& Q\left(x_{i}\right)=\left(x_{i \max }-x_{i j}\right) /\left(x_{i \max }-x_{i \min }\right)
\end{aligned}
$$

where $Q\left(x_{i}\right)$ is the indicator score; $x_{i j}$ is the value of the selected soil property, such as soil organic matter; and $x_{i \min }$ and $x_{i \max }$ are the minimum and maximum values of the soil property, respectively.

The weighted factor was used to indicate the importance of each indicator to the integrated soil quality indices. The eigenvalue, cumulative proportion of principal components, and component capacity score coefficient values were calculated by the membership values using SPSS. The weighted factors of the integrated soil quality indices $\left(W_{i}\right)$ were then calculated from the component capacity (Eq. 3).

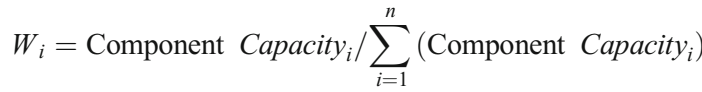

The component capacity is the score coefficient of the soil quality factor calculated by the following equation: cumulative proportion of principal components $\times$ component capacity score coefficient/eigenvalue.

SQI was derived by multiplying the weighted factors and the membership functions (Eq. 4). 
$\mathrm{SQI}=\sum_{i=1}^{n} W_{i} \times Q\left(x_{i}\right)$

The distance of $50 \mathrm{~m}$ from the pipeline was used as a control. We calculated the ratio of the SQI for the trench, piling, and working areas and $20 \mathrm{~m}$ from the pipeline to the control. Higher ratios indicate better soil quality.

\section{Soil restoration index}

The SRI was calculated using the following equation (Eq. 5):

$\mathrm{SRI}=1+\mathrm{SDI}$

where SDI is the soil deterioration index. An SRI $<1$ indicates soil deterioration, while SRI $>1$ shows an improvement in soil quality.

The SDI was calculated on the assumption that the status of the individual soil properties in areas subjected to disturbance had changed from that of the adjacent soil (Adejuwon and Ekanade 1988). The SDI was calculated using the following equation (Eq. 6):

$\mathrm{SDI}=\sum_{i=1}^{n}\left(\left(x_{i}-\bar{x}\right) / \bar{x}_{i}\right) \times 100 \% / n$

where $x_{i}$ is the value of the soil property under disturbance $\left(0,10\right.$, and $20 \mathrm{~m}$ from the pipeline) and $\bar{x}_{i}$ is the soil property of the control ( $50 \mathrm{~m}$ from the pipeline).

\section{Results}

Effects of pipeline installation on soil characteristics

In general, several surface soil properties $(0-10 \mathrm{~cm})$ changed significantly at different distances from the pipelines at sites 1 and 2 (Tables 1 and 2). The topsoil $(0-10 \mathrm{~cm})$ in the trench, piling, and working areas had lower levels of AN, AP, TN, TP, and SOM than the topsoil 20 and $50 \mathrm{~m}$ from the pipeline. In particular, the levels of AN and AP $50 \mathrm{~m}$ from the pipeline were much higher $(P<0.05)$ than those inside the ROW (trench, piling, and working areas) at sites 1 and 2 . The topsoil in the trench area had the least AN, AP, TP, and SOM at both sites 1 and 2 . However, the $\mathrm{pH}$ of the topsoil increased in the trench area at both sites. The working area had the least clay at both sites. At site 2, SOM levels were significantly $(P<0.05)$ higher at 20 and $50 \mathrm{~m}$ from the pipeline and were almost twice as high as in the ROW. The levels of TK and TC in the topsoil at site 2 were also higher at 20 and $50 \mathrm{~m}$ than those in the ROW area. There were no statistical changes in the levels of $\mathrm{TP}, \mathrm{TN}, \mathrm{TK}, \mathrm{TC}, \mathrm{SOM}$, or clay, or in the $\mathrm{pH}$ values at distances of between 20 and $50 \mathrm{~m}$ at both sites.

Generally, the levels of AN, TN, and SOM in the subsoil (10-20 and 20-40 cm) were lower in the trench than in the control areas of sites 1 and 2. Soil in the trench at a depth of $10-20 \mathrm{~cm}$ had a higher $\mathrm{pH}$ than in the other areas at both sites. The properties of the subsoil in the piling and working areas showed almost no significant change at distances of 20 and $50 \mathrm{~m}$. The TK and clay contents of the subsoil at both sites showed no clear pattern of change among the different pipeline zones.

\section{Effects of pipeline installation on soil quality}

It was assumed that the principal components with the highest eigenvalues represented the greatest variation in soil quality. Therefore, only the principal components with eigenvalues larger than 1 were examined (Andrews et al. 2002). $W_{i}$ for site 1 was calculated from the component capacity scores for PC1, PC2, PC3, and PC4 as the eigenvalues of these four PCs exceeded 1 and the cumulative proportion of variance explained reached $74.78 \%$, which was the highest variability explained in the soil data (Table 3). Similarly, $W_{i}$ for site 2 was calculated from the component capacity scores of $\mathrm{PC} 1, \mathrm{PC} 2$, and $\mathrm{PC} 3$, and the cumulative proportion of variance explained reached $76.48 \%$ (Table 4 ). The ratios of the integrated SQI values of disturbed soils $(0,10$, and $20 \mathrm{~m}$ from the pipeline) to undisturbed soil ( $50 \mathrm{~m}$ from the pipeline) were computed on the assumption that a ratio of 1 indicated that the disturbed soils were once the same as the adjacent undisturbed soils. Interestingly, the changes in the SQI in different zones showed a "V" pattern, with the lowest SQI at the center of the pipeline at site 1 (Fig. 3a). The trench area at this site had the lowest SQI value $(P<0.05)$, which was $62.2 \%$ of the undisturbed soil value. The SQI values in the piling and working areas were higher than that in the trench area, and they were only about $20 \%$ lower than in the undisturbed soil. The SQI values $20 \mathrm{~m}$ from both sides of the pipeline (W20 and E20) were similar to that of the undisturbed soil, with SQI ratios of over $90 \%$.

The SQI for site 2 showed a pattern different from that for site 1, which displayed a "U"-shaped distribution across the pipeline (Fig. 3b). The SQI values 
Table 1 Soil properties at site 1

\begin{tabular}{|c|c|c|c|c|c|c|c|c|c|c|}
\hline Distance (m) & Depth (cm) & $\begin{array}{l}\mathrm{AN} \\
\left(\mathrm{mg} \mathrm{kg}^{-1}\right)\end{array}$ & $\begin{array}{l}\text { AP } \\
\left(\mathrm{mg} \mathrm{kg}^{-1}\right)\end{array}$ & $\mathrm{pH}$ & $\begin{array}{l}\mathrm{TN} \\
\left(\mathrm{g} \mathrm{kg}^{-1}\right)\end{array}$ & $\begin{array}{l}\mathrm{TP} \\
\left(\mathrm{g} \mathrm{kg}^{-1}\right)\end{array}$ & $\begin{array}{l}\mathrm{TK} \\
\left(\mathrm{g} \mathrm{kg}^{-1}\right)\end{array}$ & $\begin{array}{l}\mathrm{TC} \\
\left(\mathrm{g} \mathrm{kg}^{-1}\right)\end{array}$ & $\begin{array}{l}\text { SOM } \\
\left(\mathrm{g} \mathrm{kg}^{-1}\right)\end{array}$ & $\begin{array}{l}\text { Clay } \\
(\%)\end{array}$ \\
\hline E50 & \multirow[t]{7}{*}{$0-10$} & $39.90^{\mathrm{a}}$ & $30.75^{\mathrm{a}}$ & 8.20 & 1.02 & 0.66 & 16.12 & 23.77 & 12.06 & 18.87 \\
\hline E20 & & 31.27 & 22.20 & 8.22 & 0.95 & 0.64 & 17.91 & 22.95 & 12.31 & 18.53 \\
\hline Piling & & 25.20 & 16.92 & 8.18 & 0.86 & 0.62 & 17.61 & 23.03 & 11.58 & 20.06 \\
\hline Trench & & 22.07 & 14.28 & 8.27 & 0.72 & 0.60 & 17.59 & 22.13 & 9.19 & 19.50 \\
\hline Working & & 23.10 & 21.42 & 8.20 & 0.70 & 0.63 & 17.48 & 22.15 & 11.56 & 18.48 \\
\hline W20 & & 31.50 & 22.77 & 8.21 & 0.96 & 0.66 & 17.53 & 22.54 & 11.91 & 18.76 \\
\hline W50 & & $36.87^{\mathrm{a}}$ & $31.38^{\mathrm{a}}$ & 8.22 & 0.86 & 0.69 & 16.28 & 21.98 & 13.52 & 20.04 \\
\hline E50 & \multirow[t]{7}{*}{$10-20$} & 31.50 & 11.70 & 8.23 & 0.88 & 0.63 & 16.40 & 22.53 & 12.54 & 20.25 \\
\hline E20 & & 26.37 & 14.78 & 8.31 & 0.88 & 0.59 & 17.02 & 22.19 & 10.94 & 20.11 \\
\hline Piling & & 26.83 & 13.77 & 8.24 & 0.79 & 0.62 & 16.61 & 22.13 & 9.68 & 12.30 \\
\hline Trench & & 18.20 & 16.67 & 8.31 & 0.57 & 0.61 & 16.96 & 21.31 & 9.33 & 20.26 \\
\hline Working & & 18.43 & 12.89 & 8.27 & 0.56 & 0.56 & 16.84 & 20.64 & 7.76 & 21.47 \\
\hline W20 & & 24.97 & 10.38 & 8.28 & 0.74 & 0.58 & 16.31 & 20.31 & 9.99 & 20.55 \\
\hline W50 & & 28.70 & 17.17 & 8.22 & $0.93^{\mathrm{a}}$ & 0.62 & 16.65 & 20.41 & 12.06 & 20.25 \\
\hline E50 & \multirow[t]{7}{*}{$20-40$} & 24.27 & 20.25 & 8.31 & 0.63 & 0.67 & 15.68 & 20.15 & 8.34 & 18.70 \\
\hline E20 & & 19.13 & 12.58 & 8.26 & 0.62 & 0.55 & 16.41 & 20.23 & 7.99 & 21.51 \\
\hline Piling & & 19.37 & 19.31 & 8.32 & 0.69 & 0.59 & 16.47 & 20.63 & 9.22 & 21.88 \\
\hline Trench & & 18.90 & 17.67 & 8.29 & 0.56 & 0.57 & 15.94 & 21.26 & 8.27 & 20.77 \\
\hline Working & & 15.17 & 16.42 & 8.38 & 0.48 & 0.56 & 17.21 & 20.05 & 6.48 & 22.20 \\
\hline W20 & & 18.20 & 11.38 & 8.25 & 0.65 & 0.53 & 16.25 & 19.28 & 8.14 & 20.37 \\
\hline W50 & & 19.60 & 20.19 & 8.39 & 0.72 & 0.47 & 15.64 & 17.04 & 14.03 & 20.22 \\
\hline
\end{tabular}

Sites located east of the pipeline are indicated using E, while those located west of the pipeline are indicated using $\mathrm{W}$

$A N$ is alkali hydrolyzable nitrogen, $A P$ available phosphorus, $T N$ soil total nitrogen, $T P$ total phosphorus, $T K$ total potassium, $T C$ soil total carbon, $S O M$ soil organic matter

${ }^{a}$ Significantly different within each row in the same depth $(P<0.05)$

for the trench, piling, and working areas in the ROW were decreased and their ratios to the undisturbed soil (at $50 \mathrm{~m}$ ) were only $51.77,55.47$, and $50.63 \%$, respectively. The SQI values $20 \mathrm{~m}$ from both sides of the pipeline (N20 and S20) were significantly higher $(P<0.05)$ than that of the ROW at site 2 . Note that the SQI value $20 \mathrm{~m}$ from the north of the pipeline (N20) was slightly higher than $50 \mathrm{~m}$, indicating possible natural soil variability.

At site 3, the three pipelines were built at different times: WEGP I was built 8 years ago, WCOP 6 years ago, and WEGP II 2 years ago. WCOP had the highest SRI in the ROW compared with that in the same pipeline zones of WEGP I and WEGP II (Fig. 4). The SRI in the WCOP trench was $98.60 \%$, indicating that it had almost recovered to its undisturbed state. The SRI in the WCOP working area was larger than $100 \%$, indicating that the soil around this pipeline had recovered to the undisturbed state. The SRI values $20 \mathrm{~m}$ from the three pipelines were all larger than $100 \%$, showing full restoration. The SRI values were much lower than $100 \%$ in the trench areas of WEGP I and WEGP II, indicating that the soil had not recovered from the construction disturbance. Although WEGP I was the oldest pipeline and had the longest time to recover, the finding that it had the lowest SRI in the ROW area may be attributable to the incomplete removal of the building materials such as gravel from the trenching.

\section{Discussion}

Clearance of vegetation and topsoil removal for pipeline installation may strongly affect soil properties, particularly in steep hilly areas (Yu et al. 2010). After the native vegetation has been destroyed, soil erosion may be aggravated and land productivity may decline. 
Table 2 Soil properties at site 2

\begin{tabular}{|c|c|c|c|c|c|c|c|c|c|c|}
\hline Distance (m) & Depth $(\mathrm{cm})$ & $\begin{array}{l}\mathrm{AN} \\
\left(\mathrm{mg} \mathrm{kg}^{-1}\right)\end{array}$ & $\begin{array}{l}\text { AP } \\
\left(\mathrm{mg} \mathrm{kg}^{-1}\right)\end{array}$ & $\mathrm{pH}$ & $\begin{array}{l}\mathrm{TN} \\
\left(\mathrm{g} \mathrm{kg}^{-1}\right)\end{array}$ & $\begin{array}{l}\mathrm{TP} \\
\left(\mathrm{g} \mathrm{kg}^{-1}\right)\end{array}$ & $\begin{array}{l}\mathrm{TK} \\
\left(\mathrm{g} \mathrm{kg}^{-1}\right)\end{array}$ & $\begin{array}{l}\mathrm{TC} \\
\left(\mathrm{g} \mathrm{kg}^{-1}\right)\end{array}$ & $\begin{array}{l}\text { SOM } \\
\left(\mathrm{g} \mathrm{kg}^{-1}\right)\end{array}$ & $\begin{array}{l}\text { Clay } \\
(\%)\end{array}$ \\
\hline N50 & \multirow[t]{7}{*}{$0-10$} & $40.83^{\mathrm{a}}$ & 30.69 & 8.38 & $1.45^{\mathrm{a}}$ & 1.03 & 18.15 & $30.67^{\mathrm{a}}$ & $18.69^{\mathrm{a}}$ & 21.38 \\
\hline $\mathrm{N} 20$ & & $38.37^{\mathrm{a}}$ & $44.84^{\mathrm{a}}$ & 8.46 & $1.47^{\mathrm{a}}$ & 1.01 & 18.73 & $29.99^{\mathrm{a}}$ & $19.08^{\mathrm{a}}$ & 21.66 \\
\hline Piling & & 23.17 & 12.39 & 8.46 & 0.77 & 0.72 & 17.06 & 21.28 & 12.20 & 24.24 \\
\hline Trench & & 15.63 & 17.36 & 8.67 & 0.70 & 0.62 & 16.89 & 21.00 & 11.27 & 24.49 \\
\hline Working & & 18.20 & 19.18 & 8.54 & 0.69 & 0.75 & 17.06 & 20.88 & 12.02 & 22.05 \\
\hline S20 & & 21.70 & 24.72 & 8.44 & 1.33 & 0.86 & 17.51 & 28.89 & $20.54^{\mathrm{a}}$ & 24.08 \\
\hline S50 & & $46.63^{\mathrm{a}}$ & 34.47 & 8.17 & 1.31 & $1.15^{\mathrm{a}}$ & 18.28 & 26.01 & $24.02^{\mathrm{a}}$ & 22.54 \\
\hline N50 & \multirow[t]{7}{*}{$10-20$} & 38.97 & 9.87 & 8.48 & 0.87 & 0.65 & 18.36 & 23.84 & 13.93 & 28.44 \\
\hline $\mathrm{N} 20$ & & 31.50 & 17.86 & 8.39 & 0.86 & 0.71 & 18.16 & 23.66 & 10.72 & 22.96 \\
\hline Piling & & 23.10 & 17.48 & 8.51 & 0.88 & 0.73 & 18.43 & 23.28 & 11.07 & 23.83 \\
\hline Trench & & 18.53 & 14.40 & 8.54 & 0.55 & 0.89 & 18.06 & 16.94 & 12.19 & 24.34 \\
\hline Working & & 25.67 & 20.44 & 8.43 & 0.91 & 0.80 & 17.66 & 23.34 & 10.86 & 23.03 \\
\hline S20 & & 34.87 & 13.14 & 8.52 & 0.87 & 0.69 & 17.02 & 23.26 & 10.82 & 26.19 \\
\hline S50 & & 36.23 & 17.74 & 8.37 & 1.26 & 0.81 & 18.57 & 27.17 & 12.35 & 23.14 \\
\hline N50 & \multirow[t]{7}{*}{$20-40$} & 24.50 & 11.07 & 8.45 & 0.68 & 0.59 & 18.12 & 22.69 & 8.62 & 29.47 \\
\hline $\mathrm{N} 20$ & & 20.30 & $22.89^{\mathrm{a}}$ & 8.46 & 0.61 & 0.65 & 17.66 & 22.93 & 7.01 & 23.28 \\
\hline Piling & & 22.87 & 14.53 & 8.58 & 0.63 & 0.63 & 16.81 & 20.06 & 9.83 & 24.62 \\
\hline Trench & & 19.87 & 15.97 & 8.49 & 0.61 & 0.62 & 17.16 & 19.56 & 6.71 & 22.35 \\
\hline Working & & 29.43 & $23.52^{\mathrm{a}}$ & 8.42 & 0.99 & $0.85^{\mathrm{a}}$ & 17.21 & 24.53 & 13.47 & 18.98 \\
\hline S20 & & 25.90 & 10.44 & 8.57 & 0.62 & 0.59 & 17.11 & 20.20 & 9.08 & 24.00 \\
\hline $\mathrm{S} 50$ & & 34.53 & 12.39 & 8.53 & 0.68 & 0.62 & 17.76 & 20.98 & 9.26 & 24.74 \\
\hline
\end{tabular}

Sites located north of the pipeline are indicated using $\mathrm{N}$, while those located south of the pipeline were indicated using $\mathrm{S}$

$A N$ alkali hydrolyzable nitrogen, $A P$ available phosphorus, $T N$ soil total nitrogen, $T P$ total phosphorus, $T K$ total potassium, $T C$ soil total carbon, $S O M$ soil organic matter

${ }^{\text {a }}$ Significantly different within each row in the same depth $(P<0.05)$

At present, there are few studies in the literature on the effects of pipeline construction on soil quality.

Effect of distance from pipeline construction on soil properties

Our finding of the lower TN and SOM levels in the topsoil inside the pipeline corridor (trench, piling, and

Table 3 Results of the principal component analysis of the integrated soil quality index at site 1

\begin{tabular}{lrrrr}
\hline & PC1 & PC2 & PC3 & PC4 \\
\hline Eigenvalue & 3.17 & 2.02 & 1.21 & 1.07 \\
Proportion & 31.69 & 20.22 & 12.14 & 10.73 \\
Cumulative proportion & 31.69 & 51.91 & 64.05 & 74.78 \\
Weighted factor & 0.08 & 0.08 & 0.08 & 0.05
\end{tabular}

working areas) is consistent with Kowaljow and Rostagno (2008) and Soon et al. (2000a). Soil affected by pipeline construction is characterized by low levels of TN and SOM (Coiffait-Gombault et al. 2012). As part of the mitigation measures implemented during the construction, the topsoil was removed and stockpiled. However, this measure decreased the organic matter and nitrogen content of the soil because of enhanced

Table 4 Results of the principal component analysis of the integrated soil quality index at site 2

\begin{tabular}{lrrrr}
\hline & PC1 & PC2 & PC3 & PC4 \\
\hline Eigenvalue & 5.44 & 1.17 & 1.04 & 0.76 \\
Proportion & 54.39 & 11.72 & 10.38 & 7.65 \\
Cumulative proportion & 54.39 & 66.11 & 76.48 & 84.13 \\
Weighted factor & 0.07 & 0.07 & 0.06 & 0.08 \\
\hline
\end{tabular}



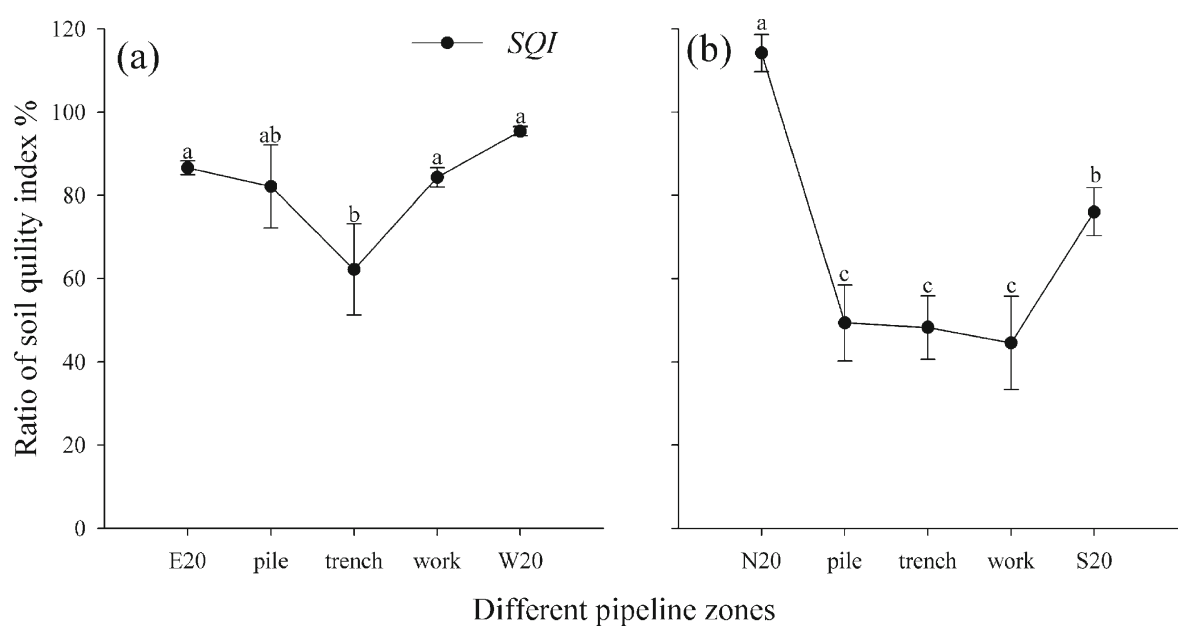

Fig. 3 Ratios of the integrated soil quality index ( $S Q I$ ) values for disturbed areas $(0,10$, and $20 \mathrm{~m}$ from the pipeline) to those for the undisturbed area (50 $\mathrm{m}$ from the pipeline) at site 1 (a) and site

decomposition (Soon et al. 2000b). The topsoil suffered much more disturbance than the subsoil due to soil horizon mixing, soil compaction, and topsoil removal (Yu et al. 2010). Topsoil in the trench area had lower levels of AN, AP, TP, and SOM than the undisturbed soil. The soil properties in the trench area may have been altered because of the inverted soil profiles. Mixing and dilution of the topsoil with subsoil materials in the trench area would accelerate the mineralization of nitrogen compounds and carbonaceous materials, resulting in a decrease in total nitrogen of $20 \%$ and soil

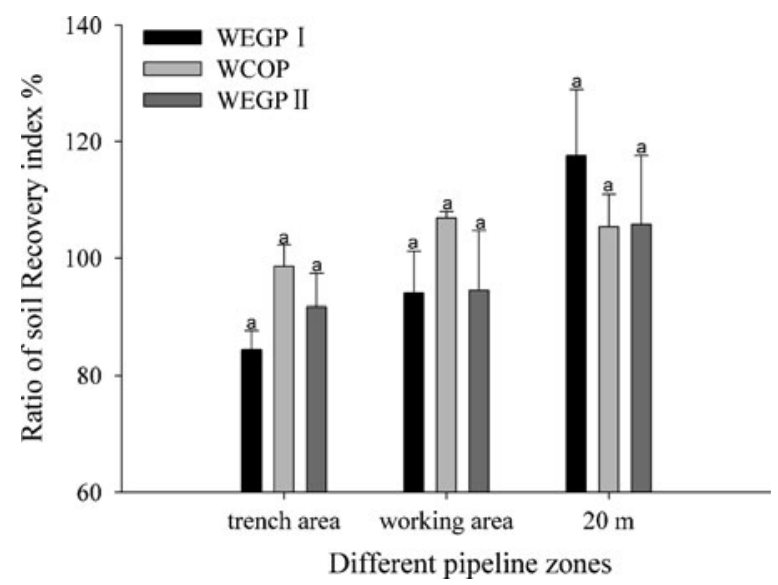

Fig. 4 Soil restoration index at distances of $0 \mathrm{~m}$ (trench area), $10 \mathrm{~m}$ (working area), and $20 \mathrm{~m}$ from the pipeline at site 3. WEGP I was completed 8 years ago, WCOP 6 years ago, and WEGP II 2 years ago. Values are the means $\pm \mathrm{SD}(n=3)$. The same letter indicates no significant difference
2 (b). Values are the means $\pm \mathrm{SD}(n=3)$. Different letters indicate significant difference at the 0.05 level

organic matter of $9 \%$ (Soon et al. 2000a). In this study, the $\mathrm{pH}$ of the topsoil in the trench areas increased by about 0.2 units. Exchangeable $\mathrm{Ca}$ affected by the trenches has been reported to be strongly correlated with soil pH (Soon et al. 2000b). During excavation, the calcareous matrix is dug from the subsoil, which liberates calcium ions and increases the soil $\mathrm{pH}$ (Coiffait-Gombault et al. 2012). It is suggested that the topsoil bulk densities of the ROW areas may be significantly higher than those of undisturbed areas due to intense compaction by the traffic of heavy machinery (Soon et al. 2000b). Soil porosity is reduced by pipeline installation, as bulk density is inversely related to porosity, which may decrease soil microbial activity and affect soil carbon and nitrogen cycling. The soil properties $20 \mathrm{~m}$ from the pipeline were almost the same as those of the undisturbed soil $50 \mathrm{~m}$ from the pipeline, which may indicate either less disturbance from construction or rapid recovery at this border line.

The results of this study suggest that the zones with impaired topsoil properties followed the sequence trench $>$ piling and working areas $>20 \mathrm{~m}$. The topsoil $(0-10 \mathrm{~cm})$ in the ROW area suffered more disturbance than the subsoil (10-20 and 20-40 cm).

Effects of topography on soil disturbance from pipeline construction

The maintenance of soil quality is critical to the sustainability of agro-ecosystems (Arshad and Martin 
2002). It is interesting that the SQI presented a spatial "V" pattern at site 1, but a "U-shaped" distribution at site 2. At site 1, the lowest SQI value was obtained in the trench area, and it increased linearly with the distance up to $20 \mathrm{~m}$. A different spatial pattern was obtained at site 2, where the SQI value in the trench area was about the same as those in the piling and working areas. Pingliang is located in a hillier region than Xi'an, which limited the use of heavy machinery and required smaller and lighter equipment for the pipeline construction. As a result, there was less soil disturbance by traffic at site 1 than at site 2 . In contrast, the heavier machinery used at the much flatter site 2 may have caused more soil compaction. Therefore, the SQI of site 1 had more local variation within the ROW area (i.e., higher SQI values in the piling and working areas than that in the trench). These results are consistent with the findings of Cui et al. (2009) that the variation in the soil total nitrogen and organic matter in the steep area formed a "V" shape, with the lowest value close to the road construction surface.

A natural gas or oil pipeline is a linear project routed through varied topography (i.e., hilly and flat). The results showed that the site topography may influence the affected area due to the different movement patterns of heavy machinery and traffic routes. This suggests that the variation in soil disturbance during pipeline installation with differing topography should be considered in EIAs.

Temporal duration of soil restoration

Soon et al. (2000a) reported a significant decrease in soil total nitrogen in the pipeline ROW area following pipeline installation, but it was no longer evident 2 years after pipeline construction. This finding suggests that the disturbance from trenching and machinery trampling may be restored within a few years of construction through natural restoration and agricultural management. Restoration of a soil system to high productivity requires several years (Chen and Gao 2006). Although follow-up environmental assessments are conducted after construction, they are difficult to implement accurately because the length of time needed for restoration is unclear. Fewer studies have paid attention to the integrated index for assessing soil restoration after pipeline installation. The soil in the corridor of WCOP had almost recovered to its undisturbed state after 6 years of agricultural management. Taking the restoration duration into consideration in the follow-up assessment program would improve the

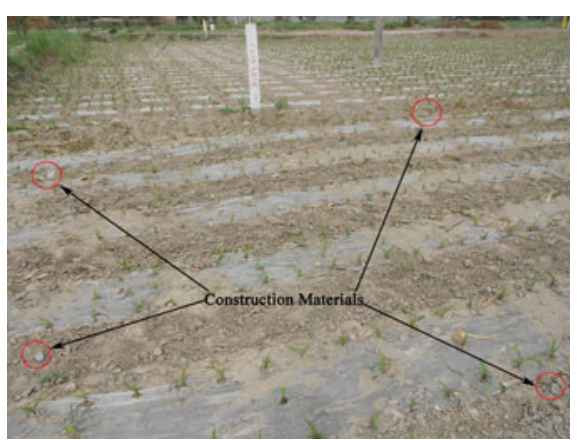

Fig. 5 Incomplete cleanup of construction materials (gravel from trenching) and lack of follow-up mitigation measures of WEGP I, site 3

accuracy and effectiveness of EIAs. Generally, the SRI values at site 3 were higher in the working areas than in the trench areas of all three pipelines with different restoration periods. The extent of soil restoration varied between zones, which may be attributable to the different intensities of disturbance from the construction. As discussed, trenching resulted in more serious disturbance than compaction by heavy machinery and traffic in the working area. WEGP I was the first long gas pipeline to be constructed from West to East China. Although great efforts were made to conduct EIAs, serious ecological restoration problems still need to be addressed. Despite having had the longest time to recover, the restoration of WEGP I was worse than that of WCOP and WEGP II. The investigation showed that the continued disturbance of WEGP I was due to the incomplete cleanup of the construction materials, as shown in Fig. 5.

The results indicate that it generally takes 6 years for soil to fully recover. Persistent disturbance and a lack of follow-up mitigation measures may hinder the progress of soil restoration after disturbance.

\section{Conclusion}

Soil systems provide critical support for farmland productivity; thus, further research on soil quality is necessary to guide pipeline construction and restoration. The accurate determination of the affected area and the restoration cycle for EIA practices is a relevant and complex issue. This study discovered that the effects of pipeline installation on soil properties were mainly evident within the pipeline corridor. The level of impairment in different zones followed the pattern of trench $>$ piling and 
working areas $>20 \mathrm{~m}$. The results of this study provide a reference for determining the spatial extent of soil assessment for EIAs. The duration of soil restoration is another important parameter for a quantitative EIA as it estimates the length of time required for the follow-up mitigation and farmland compensation. Our results indicate that soil rehabilitation may be complete 6 years after the completion of a pipeline installation project. However, there may be exceptions, as in the case of WEGP I where the incomplete cleanup of building materials and lack of follow-up mitigation measures hindered the progress of soil restoration. Topography should also be considered in a pipeline's EIA, as this study shows that site topography may change the intensity of disturbance in different pipeline zones.

Acknowledgments This work was financially supported by the Industry Research Project on Environmental Protection (201209029). The author also would like to thank Dr. Wenlin Chen for his valuable suggestion and for polishing the English.

\section{References}

Adejuwon, J. O., \& Ekanade, O. (1988). A comparison of soil properties under different landuse types in a part of the Nigerian cocoa belt. Catena, 15, 319-331.

Andrews, S. S., Karlen, D. L., \& Mitchell, J. P. (2002). A comparison of soil quality indexing methods for vegetable production systems in northern California. Agriculture, Ecosystems \& Environment, 90, 25-45.

Arshad, M. A., \& Martin, S. (2002). Identifying critical limits for soil quality indicators in agro-ecosystems. Agriculture, Ecosystems \& Environment, 88, 153-160.

Bone, J., Head, M., Barraclough, D., Archer, M., Scheib, C., Flight, D., et al. (2010). Soil quality assessment under emerging regulatory requirements. Environment International, 36, $609-622$.

Canadian Environmental Assessment Agency. (1996). A reference guide for the Canadian Environmental Assessment Act: assessing environmental effects on physical and cultural heritage resources. Hull, Quebec.

Chen, L. D., \& Gao, Q. C. (2006). Chance and challenge for China on ecosystem management: lessons from the Westto-East pipeline project construction. Ambio, 35, 91-93.

Chen, L. D., Tian, H. Y., Zhang, X. Y., Feng, X. M., \& Yang, W. H. (2012). Public attitudes and perceptions to the West-toEast pipeline project and ecosystem management in large project construction. International Journal of Sustainable Development and World Ecology, 19, 219-228.

Coiffait-Gombault, C., Buisson, E., \& Dutoit, T. (2011). Hay transfer promotes establishment of Mediterranean steppe vegetation on soil disturbed by pipeline construction. Restoration Ecology, 19, 214-222.
Coiffait-Gombault, C., Buisson, E., \& Dutoit, T. (2012). Are old Mediterranean grasslands resilient to human disturbances? Acta Oecologica-International Journal of Ecology, 43, 86-94.

Cornfield, A. H. (1960). Ammonia released on treating soils with $\mathrm{N}$ sodium hydroxide as a possible means of predicting the nitrogen-supplying power of soils. Nature, 187, 260-261.

Cui, B. S., Zhao, S., Zhang, K., Li, S., Dong, S., \& Bai, J. (2009). Disturbance of Dabao highway construction on plant species and soil nutrients in Longitudinal Range Gorge Region (LRGR) of southwestern China. Environmental Monitoring and Assessment, 158, 545-559.

Desserud, P., Gates, C. C., Adams, B., \& Revel, R. D. (2010). Restoration of foothills rough fescue grassland following pipeline disturbance in southwestern Alberta. Journal of Environmental Management, 91, 2763-2770.

Fu, B. J., Liu, S. L., Lu, Y. H., Chen, L. D., Ma, K. M., \& Liu, G. H. (2003). Comparing the soil quality changes of different land uses determined by two qualitative methods. Journal of Environmental Sciences, 15, 167-172.

João, E. (2002). How scale affects environmental impact assessment. Environmental Impact Assessment Review, 22, 289-310.

Karlen, D. L., Mausbach, M. J., Doran, J. W., Cline, R. G., Harris, R. F., \& Schuman, G. E. (1997). Soil quality: a concept, definition, and framework for evaluation. Soil Science Society of America Journal, 61, 4-10.

Karstens, S. A. M., Bots, P. W. G., \& Slinger, J. H. (2007). Spatial boundary choice and the views of different actors. Environmental Impact Assessment Review, 27, 386-407.

Kaufmann, M., Tobias, S., \& Schulin, R. (2009). Quality evaluation of restored soils with a fuzzy logic expert system. Geoderma, 151, 290-302.

Kowaljow, E., \& Rostagno, C. M. (2008). Gas-pipeline installation effects on superficial soil properties and vegetation cover in northeastern Chubut. Ciencia del Suelo, $26,51-62$.

Mueller, L., Shepherd, G., Schindler, U., Ball, B. C., Munkholm, L. J., Hennings, V., et al. (2013). Evaluation of soil structure in the framework of an overall soil quality rating. Soil \& Tillage Research, 127, 74-84.

Olson, E. R., \& Doherty, J. M. (2012). The legacy of pipeline installation on the soil and vegetation of southeast Wisconsin wetlands. Ecological Engineering, 39, 53-62.

Patzel, N., Sticher, H., \& Karlen, D. L. (2000). Soil fertilityphenomenon and concept. Journal of Plant Nutrition and Soil Science, 163, 129-142.

Romaniuk, R., Giuffre, L., Costantini, A., Bartoloni, N., \& Nannipieri, P. (2011). A comparison of indexing methods to evaluate quality of soils: the role of soil microbiological properties. Soil Research, 49, 733-741.

Sims, J. R., \& Haby, V. A. (1971). Simplified colorimetric determination of soil organic matter. Soil Science, 112, 137-141.

Soon, Y. K., Arshad, M. A., Rice, W. A., \& Mills, P. (2000a). Recovery of chemical and physical properties of boreal plain soils impacted by pipeline burial. Canadian Journal of Soil Science, 80, 489-497.

Soon, Y. K., Rice, W. A., Arshad, M. A., \& Mills, P. (2000b). Effect of pipeline installation on crop yield and some 
biological properties of boreal soils. Canadian Journal of Soil Science, 80, 483-488.

Woodward, C. L. (1996). Soil compaction and topsoil removal effects on soil properties and seedling growth in Amazonian Ecuador. Forest Ecology and Management, 82, 197-209.

Yu, X. F., Wang, G. P., Zou, Y. C., Wang, Q., Zhao, H. M., \& Lu, X. G. (2010). Effects of pipeline construction on wetland ecosystems: Russia-China oil pipeline project (Mohe-Daqing section). Ambio, 39, 447-450.

Zornoza, R., Mataix-Solera, J., Guerrero, C., Arcenegui, V., García-Orenes, F., Mataix-Beneyto, J., et al. (2007). Evaluation of soil quality using multiple lineal regression based on physical, chemical and biochemical properties. Science of the Total Environment, 378, 233-237. 